\title{
The Effects of Drawings on Permanent Anatomy Education
}

\section{Kavak V*}

Department of Anatomy, Medical Faculty, Dicle University, Diyarbakir, Turkey

*Corresponding Author: Kavak V, Department of Anatomy, Medical Faculty, Dicle University, Diyarbakir, Turkey. E-mail: vatankavak@gmail.com
Received: March 22, 2021

Published: April 09, 2021

(C) All rights are reserved by Kavak V.

\section{Abstract}

The aim of this study was to determine the method for students to learn permanent anatomy from the studies of anatomists who have worked before in anatomy education.

This study was conducted on 1202 students studying anatomy in five faculties and high schools. In order to determine the impacts of permanent anatomy education, 2 questions were asked to the students included in the study.

a) Should the anatomy lesson be given as a slide presentation in the classroom?

b) Under the supervision of an anatomist; To make the anatomical drawing of the opened area of the student after cadaver dissection in the laboratory.

Based on the answers how anatomy education should be, 95.5\%, 72.4\%, 82.4\%, 47.7, and 44.4\% of students repectively in faculties of medical, pharmacy, Dentistery, Vacational and Physical and Sports students stated cadaver dissection and drawing under an antomist direction. Also 4.5\%, 27.6\%, 17.6\%, 53.3\%, and 55.6\% respectively in faculties of medical, pharmacy, Dentistery, Vacational, andPhysical and Sports prefered slide presentation in anatomical education in order to permanent impact.

As a result, to achieve success in permanent anatomy education; It is essential to establish cadaver halls, Cadaver theater halls, Anatomy museums and equipped drawing halls.

Keywords: Anatomy Education; Anatomical Drawings; Cadaver Dissection; Cadaver Theater Halls; Anatomy Museums

\section{Introduction}

Galen, the last anatomy of the ancient age, is the anatomical information compiled from previous anatomists in the $2^{\text {nd }}$ century [1]. From the $3^{\text {rd }}$ to the $12^{\text {th }}$ century BC, human anatomy was learned mainly through books and animal dissection [2].

At the end of the $16^{\text {th }}$ century, while anatomists were interested in dissection technique rather than anatomy philosophy, they continued to work in anatomy theaters by pushing the boundaries of the natural philosophy of anatomy studies [3].

Vesalius' lectures and cadaver practices brought new approaches to anatomy education at the University of Montpellier (France) and Lyon University (France). The sample of Turkish textbo- oks written by Şemseddîn-i Itâkî in the $17^{\text {th }}$ century reveals two important facts in anatomy education: Literature books and books strengthened with illustrators need a common terminology for the international dissemination of anatomy knowledge. In anatomy teaching, representation of the human body was used when dissection was not allowed. "Cardboard mâché anatomical models" and wax samples were used. The ways of teaching and learning anatomy have been expanded with new tools and supports. The disintegration of human cadavers in the $17^{\text {th }}$ and $18^{\text {th }}$ centuries affected anatomy and made important contributions to anatomy studies. With the emergence of the printing press, anatomical information was shared. Since the study of anatomy is concerned with observation and drawings, the popularity of the anatomist has increased in direct proportion to the quality of drawing skills [4]. 
Josias Weitbrecht, an important researcher who lived in the $18^{\text {th }}$ century; He founded an anatomy school with syndesmology and Václav Trnka created in Slovakia and Hungary, which made a significant contribution to anatomy education [5].

The history of anatomy ranges from the earliest studies of the human body to the complex body analyzes of modern scientists. Studies of human anatomy date back to the Egyptians thousands of years ago. The mastery of the Nile Valley people in mummy art is indisputable. Today, mummy art has not developed as much as the mummy art developed 3000 years ago.

So that the development of his anatomical studies could be understood and built on concepts that were increasingly part of the traditional medicine curriculum in the Galen era, it was characterized by the functions and development of organs and anatomical structures in the human body over time [6]. Nomenclature, methods and applications for the study of anatomy are all contributions of the Greeks [7]. Leonardo da Vinci made great contributions to anatomy education with a series of anatomical drawings depicting the ideal human form. Leonardo da vinci was one of the artists who personally practiced anatomy dissection. He had a indisputable place with his anatomy studies and drawings.Vinci also has-had studies dealing with the anatomical structure of men and women mutually. His drawings about the condition of the child in the pregnant woman and the uterus are very important. Vinci emphasizes the mathematical calculation of human body structure and proportions. Numerous researchers living before and after Vinci's time contributed to the education of anatomy with their artistic works $[8,9,19]$. Vesalius made a major contribution to anatomy education by rejecting Galen's anatomical teachings based on observations of other mammals rather than the human body [10].

In the $19^{\text {th }}$ century, anatomical studies were expanded with the histology and developmental biology of both humans and animals. Anatomy theaters established in this century have made great contributions to comparative anatomy. Practices and anatomy lessons were mostly open to the public in these lecture halls where anatomy dissections continued for days. These dissections and anatomy lessons, which were done with great patience, contributed greatly to both the scientific environment and the enlightenment of the public $[11,12,19]$.
Anatomical studies over the last century have benefited from technological advances and increased understanding of sciences such as evolutionary and molecular biology to create a comprehensive understanding of the organs and structures of the body. Medical devices such as MRI machines and CAT scanners have contributed to the work of anatomists.

Developments in cadaver applications in photography have brought a new breath to anatomy education. Plastic anatomical models offer a good alternative to reality in anatomy teaching. The use of live models for anatomy demonstration is once again becoming popular in anatomy teaching $[13,14]$.

Researchers who are masters of Embryology and Anatomy; With their publications supported by schematic pictures, they have contributed to anatomy education with a new breath by choosing the most necessary information for studies in the field of anatomy and embryology [14].

Researchers, each of whom is the elite of their field; With the studies they supported with drawings by filtering previously published written and digital anatomical information; researchers gave a new direction to anatomy education [15].

A Legendary Anatomist; In his publication, he stated that he made important contributions to the history of anatomy education and the success of charcoal drawings with the work of popular anatomists who have lived around the world [18].

Anatomical drawings are one of the simplest and most effective ways to convey visual ideas. It has a very important appeal regardless of time.

Charcoal drawings are a form of expression in interaction. The expression, form and depth to be used in interaction can be achieved by adding shading, blending, dark and light tones. Especially for the medical art, measuring the dimensions of a subject while blocking it in the drawing will be an important step in producing a realistic interpretation of the subject.

The fact that anatomical illustrations look artistic, and at the same time, an artist's observation, problem solving and emphasis on composition is a reflection of the expression style. 
Anatomical Drawings are about both reading and listening. It's a powerful tool that is not only about visual but also listening $[16,17]$.

\section{Aim of the Study}

In the present study, we amied to assess the impacs of drawing on permanent anatomy learning for students.

\section{Materials and Methods}

In the present study, we amied to assess the impacs of drawing on permanent anatomy learning for students, This study was conducted 1202 on students studying anatomy in five faculties and high schools. In order to determine the future of anatomy education, 2 questions were asked to the students included in the study.

Five faculty students, Faculty of Medicine ( $n=330$ ), Faculty of Pharmacy ( $n=145)$, Faculty of Dentistry ( $n=142)$, Vocational School of Health Services $(n=450)$ and School of Physical Education Sports $(n=135)$ It was asked how the anatomy lesson should be handled.
The questions had two options:

- $\quad$ Should the anatomy lesson be given as a slide presentation in the classroom?

- Under the supervision of an anatomist; To make the anatomical drawing of the opened area of the student after cadaver dissection in the laboratory.

The preferences of the students in different faculties and schools regarding how they would like the Anatomy course to be given were taken. Evaluation was tested with the chi-square test.

The anatomical drawings shown among the findings in this study; Video images of cesarean section and placenta percreta surgery performed in the operating room of the Gynecology Clinic were shown with anatomical drawings. Before the cesarean operation, the patient's approval was obtained from the surgeon who performed this operation for anatomical drawings.

In this study, anatomical drawings drawn by me were used to contribute to permanent anatomy education after cadaver dissections.

\section{Results}

Survey result

\begin{tabular}{|c|c|c|c|c|c|}
\hline \multicolumn{6}{|c|}{ Faculties * Preferences Crosstabulation } \\
\hline \multirow{2}{*}{\multicolumn{3}{|c|}{$\begin{array}{l}\text { Presentation with slide } \\
\text { In the lab setting Cadaver dissection and drawing }\end{array}$}} & \multicolumn{2}{|c|}{ Preferences } & \multirow{3}{*}{$\begin{array}{l}\text { Total } \\
330\end{array}$} \\
\hline & & & & & \\
\hline \multirow[t]{10}{*}{ Faculties } & \multirow[t]{2}{*}{ Medicine } & Count & 15 & 315 & \\
\hline & & $\%$ within faculties & $4,5 \%$ & $95,5 \%$ & $100,0 \%$ \\
\hline & \multirow[t]{2}{*}{ Pharmacy } & Count & 40 & 105 & 145 \\
\hline & & $\%$ within faculties & $27,6 \%$ & $72,4 \%$ & $100,0 \%$ \\
\hline & \multirow[t]{2}{*}{ Dentist } & Count & 25 & 117 & 142 \\
\hline & & $\%$ within faculties & $17,6 \%$ & $82,4 \%$ & $100,0 \%$ \\
\hline & \multirow{2}{*}{$\begin{array}{l}\text { Health Vocational } \\
\text { School }\end{array}$} & Count & 240 & 210 & 450 \\
\hline & & $\%$ within faculties & $53,3 \%$ & $46,7 \%$ & $100,0 \%$ \\
\hline & \multirow{2}{*}{$\begin{array}{l}\text { Physical education } \\
\text { sports college }\end{array}$} & Count & 75 & 60 & 135 \\
\hline & & $\%$ within faculties & $55,6 \%$ & $44,4 \%$ & $100,0 \%$ \\
\hline \multirow{2}{*}{\multicolumn{2}{|c|}{$\begin{array}{l}\text { Total } \\
\text { hin faculties }\end{array}$}} & Count & 395 & 807 & 1202 \\
\hline & & $32,9 \%$ & $67,1 \%$ & $100,0 \%$ & \\
\hline
\end{tabular}

Table 1: Answers given by the students to the question of how to teach anatomy lesson.

$$
\text { Chi-Square }=253,729 \mathrm{P}=0,000 \text {. }
$$


Two questions were asked to 330 students studying at the Faculty of Medicine regarding the future of anatomy education. While 15 out of 330 students preferred the course with slide presentation, 315 students preferred cadaver dissection and anatomical drawing under the supervision of an anatomist (Table 1).

Two questions were asked to the students studying anatomy at the Faculty of Pharmacy. 40 out of 145 students studying at the Faculty of Pharmacy preferred slide presentation in the classroom, while 105 students preferred cadaver dissection and drawing under the direction of an anatomist (Table 1).

25 students out of 142 students studying at the Faculty of Dentistry, who were asked about how Permanent Anatomy education should be asked, preferred the slide presentation in the classroom, while 117 students preferred cadaver dissection and drawing under the direction of the anatomist (Table 1).

When asked about two questions about how a permanent and impressive Anatomy education should be, 240 out of 450 students studying at the School of Health preferred slide presentation in the classroom, while 210 students preferred cadaver dissection and drawing under the direction of an anatomist (Table 1).

Two questions were asked about how effective and permanent anatomy education should be in the future, and 75 out of 135 students studying at the School of Physical Education and Sports preferred slide presentation in the classroom, while 60 students preferred Anatomist controlled cadaver dissection and drawing. anatomy (Table 1).

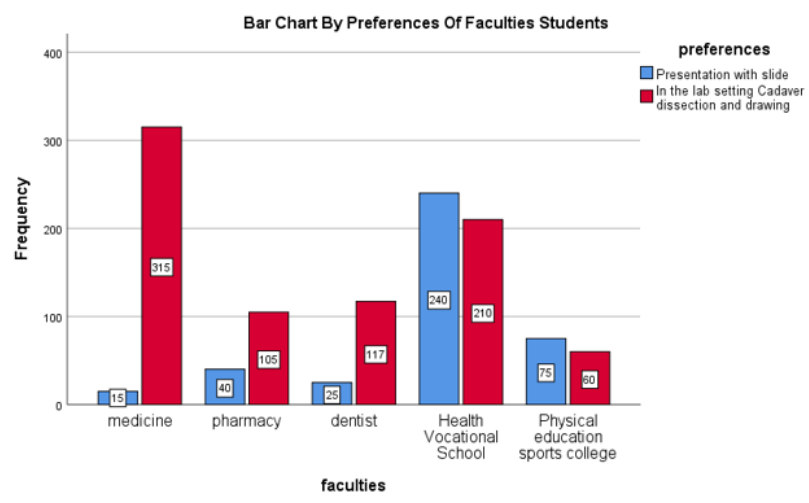

Figure 1: Bar chart by preferences of faculties students.
In figure 1, bar graphs show the distribution of student preferences according to the teaching of anatomy lesson by faculties and Health Vocational Schools. Blue bars are those who want the anatomy lesson with slides, and the red bars are those who prefer "Cadaver dissection and anatomical drawing in the laboratory environment".

According to the answers given by the students to the question of how anatomy education should be; $95.5 \%$ of 330 students studying at the medical faculty expressed their demands for cadaver dissection and drawing under the direction of an anatomist. 4.5\% of students studying at this faculty preferred lectures with a slide (Table 1).

According to the answers given by the students of the Faculty of Pharmacy to 2 questions about anatomy education; $72.4 \%$ of 145 students studying at the faculty of pharmacy stated that they preferred cadaver dissection and drawing under the direction of an anatomist. $27.6 \%$ of the students studying at this faculty preferred the lesson with slide presentation (Table 1).

According to the answers of 2 questions asked about the anatomy education of the Faculty of Dentistry; $82.4 \%$ of 142 students studying at the Faculty of Dentistry preferred cadaver dissection and drawing under the supervision of an anatomist. $17.6 \%$ of the students studying at this faculty express their preference for slide presentation (Table 1).

To the students studying anatomy at the Health Vocational School; According to the answers of 2 questions asked about anatomy education; $46.7 \%$ of 450 students studying anatomy at the Vocational School of Health expressed their demands for cadaver dissection and drawing under the supervision of an anatomist. $53.3 \%$ of the students studying anatomy at the Health Vocational School wanted lessons with slide presentations (Table 1).

According to the answer given by the School of Physical Education and Sports students to the question of how anatomy education should be; $44.4 \%$ of 135 students studying at the School of Physical Education and Sports requested cadaver dissection and drawing under the supervision of an anatomist. $55.6 \%$ of the students who took anatomy in the School of Physical Education and Sports requested that the lesson be taught with the slide in the classroom (Table 1).

Citation: Kavak V. “The Effects of Drawings on Permanent Anatomy Education". Acta Scientific Women's Health 3.5 (2021): 03-09. 

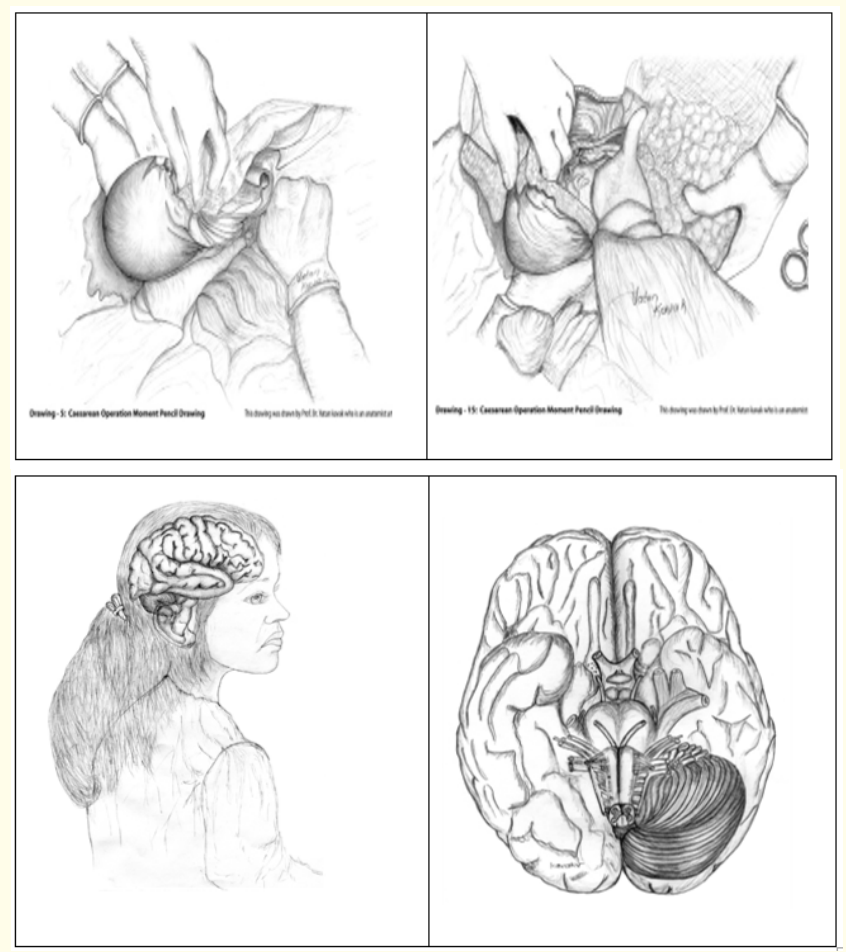

Figure 2: These drawings were drawn by Prof. Dr. Vatan Kavak, who is an anatomy artist.

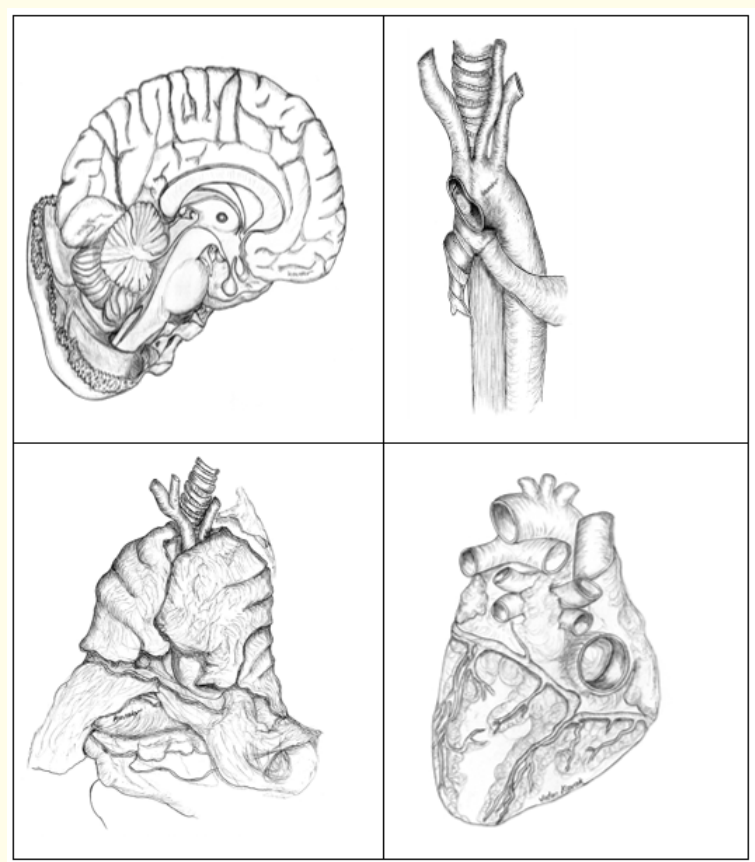

Figure 3: These drawings were drawn by Prof. Dr. Vatan Kavak, who is an anatomy artist.

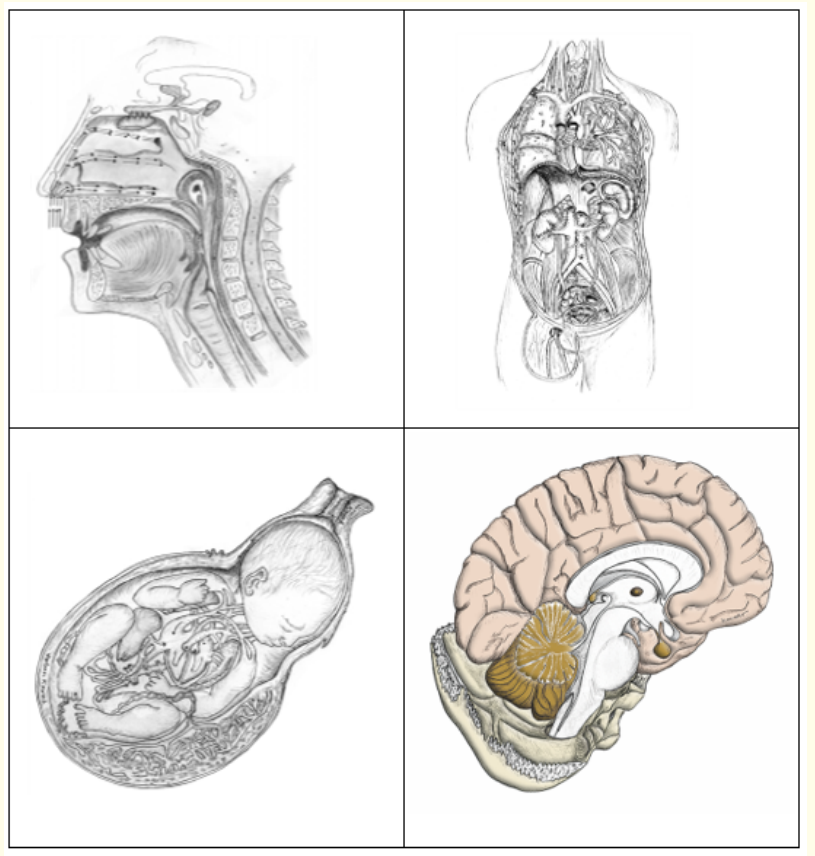

Figure 4: These drawings were drawn by Prof. Dr. Vatan Kavak, who is an anatomy artist.

\section{Discussion and Conclusion}

The results of our findings, which measure how students' permanent anatomy education should be, support Leonardo da Vinci's past cadaver dissections, indisputable drawings, and the work of other anatomists $[8,9,19]$.

Anatomy education, theoretical knowledge, cadaver applications, plastic models and charcoal drawings have been reported by anatomists who make learning stronger. This empowerment expression has been expressed by anatomists who have lived from the $18^{\text {th }}$ century to the present and are famous in their field, and the student's anatomical knowledge can be learned permanently. These explanations made by anatomists support the results of our study $[4,5]$.

Performing anatomical drawings under the direction of the anatomist after cadaver dissection constitutes the spirit of anatomy education. Anatomical drawings to be made after cadaver dissection will excite the student when they are depicted. Anatomical drawings will turn boring information into an understandable mood. The results of our study are supported by different anatomists $[4,12]$. 
Anatomy books prepared with visual anatomical drawings make it easy for students to learn. The results of our study support the findings of our study, and the studies prepared by anatomists who are popular in their field [14-17].

Anatomical drawings after cadaver dissection are a reflection of the theoretical knowledge of the anatomist. For this reason, anatomical drawings are indispensable for anatomy education. During anatomy training, the anatomist should guide the student to draw anatomical drawings. The anatomical drawings drawn by the student should be carefully studied by the anatomist. Success in anatomy education will be inevitable when anatomical drawings are made meticulously. In anatomy education, the anatomist should guide the student through anatomical drawing tirelessly and patiently [14-16].

The historical development of anatomy and the researches of the anatomist, who contributed to the education of anatomy with his invaluable works, strongly support the results of our research $[18,19]$.

Eyyubes, one of the ancient civilizations that lived in Mesopotamia, had a rich anatomy history. The valuable information Eyyubes gave about the morphology of the human body is supported by the results of our study [20].

As a result, to achieve success in permanent anatomy education; It is essential to establish cadaver halls, Cadaver theater halls, Anatomy museums and equipped drawing halls.

According to the feedback received from students who study anatomy in the field of health every year, it was determined that anatomical drawings that provide permanent learning are a powerful tool in anatomy education.

\section{Acknowledgements}

I would like to express my gratitude to Prof. Dr. Ömer SATICI, faculty member of the Faculty of Medicine, Department of Biostatistics, for whom I received scientific support in the preparation of this publication.

\section{Bibliography}

1. Siddiquey A., et al. "History of Anatomy". Bangladesh Journal of Anatomy 7.1 (2009): 1-3.
2. Siraisi N G. "Medieval and Early Renaissance Medicine". Chicago and London: University of Chicago Press. (1990): 84.

3. Klestinec C. "A History of Anatomy Theaters in Sixteenth-Century Padua". Journal of the History of Medicine 59.3 (2004): 376-379.

4. Howse C. "The myth of anatomy lesson". The Daily Telegraph. London (2010).

5. Dupar F and Grignon B D. "Editorial: History in anatomy education". Surgical and Radiologic Anatomy 41 (2019): 11011102.

6. Lindemann M. "Medicine and Society in Early Modern Europe (New Approaches to European History". Cambridge, Cambridge University Press) (2015): 91.

7. Singer CJ. "A short history of anatomy from the Greeks to Harvey: the evolution of anatomy". New York: Dover publications (1957).

8. Boas MH. "The Scientific Renaissance". New York Dover Publications 1450-1630 (2013).

9. Mason SF. "A History of the Sciences". New York: Collier (1962): 550.

10. Klestinec C. "A History of Anatomy Theaters in Sixteenth-Century Padua". Journal of the History of Medicine 59.3 (2004): 376-379.

11. McLachlan J and Patten D. "Anatomy teaching: ghosts of the past, present and future". Medical Education 40.3 (2006): 243253.

12. Reinarz J. "The age of museum medicine: The rise and fall of the medical museum at Birmingham's School of Medicine". Social History of Medicine 18.3 (20025): 419-437.

13. Diamond M. "Integrative Biology 131 - Lecture 01: Organization of Body". Berkeley, University of California (2005).

14. Boka S., et al. "Embriology and Anatomy for Healty Sciences". Riga Stradins University, Riga, Latvia (2010).

15. Pilmane M., et al. "Embriology and Anatomy for Healty Sciences”. Riga Stradins University, Riga, Latvia (2016).

16. Kavak V. "Functional Embryology and Anatomy Atlas" (2020).

17. http://www.vatankavak.com.tr/dijital-drawings.html 
18. Ortuğ G. Anatomide İz Bırakanlar; Resimli Anatomi Tarihi Biyografi Ve Eponim, Bahçeșehir Üniversitesi Yayınları,Uğur Yayın Evi,İstanbul (2015).

19. Ortuğ G. Antikçağdan Rönesansa Anatominin Kısa Tarihi, Ceylan ofset, Samsun (2013).

20. Muhammadali M., et al. "The history of anatomy in Persia". Journal of Anatomy 210 (2007): 359-378.

\section{Assets from publication with us}

- Prompt Acknowledgement after receiving the article

- Thorough Double blinded peer review

- Rapid Publication

- Issue of Publication Certificate

- High visibility of your Published work

Website: www.actascientific.com/

Submit Article: www.actascientific.com/submission.php

Email us: editor@actascientific.com

Contact us: +919182824667 